Impact of $\mathrm{pH}$ of Water on Washing Time in Automatic Washing Machine

\title{
Impact of pH of Water on Washing Time in Automatic Washing Machine
}

\author{
Saqlain, M.*and Tariq, F. R. \\ Department of Mathematics, Lahore Garrison University, Lahore, Pakistan \\ *msgondal0@gmail.com
}

\begin{abstract}
The $\mathrm{pH}$ of water is different in different areas. So, the washing machines which are based on Fuzzy Logic Controller being used in different areas are deprived of useful results because these machines cannot detect the $\mathrm{pH}$ of water. When $\mathrm{pH}$ of water is other than 7, more detergent and washing time for laundry is consumed. The proposition of the paper is that neutral water $(\mathrm{pH}=7)$ should be used in washing machines. It will reduce the washing time. In this way, energy and washing time can be saved. The impersonate results and the action of the aforementioned device have been done by fuzzy logic toolbox using MATLAB.
\end{abstract}

Keywords: $p H$ of water, automatic washing machine, MATLAB, fuzzy interface system, fuzzy logic controller (FLC).

\section{Introduction and Preliminaries}

The concept of fuzzy logic was first proposed by Lotfi A. Zadeh in 1965 [1]. The FLC based experiment was conducted by Mamdani [2] in 1974. He designed the fuzzy logic for a steam engine. Mamdani showed in his experiment that how easy it was for a computer to process linguistic inputs which was given by Zadeh. Everyday many home appliances are being upgraded using fuzzy logic to save time and to conserve electricity [3]. Since 1980, the use of FLC based system has become common in vacuum cleaner, washing machine, elevator and metro. Washing machine is commonly used in every house for cleaning and rinsing of fabric. There are two types of washing machines, namely semi-automatic and fully automatic. In Semi-automatic washing machine the user selects washing time for spinning of tube. While in automatic washing machine [4] the load is fully treated by the machine without the need for user intervention at any point during the washing process prior to its completion. Washing machines not only save energy but also have positive effects on economy and fabric. A. Agarwal et al. [5] boost the design of automatic washing machines. These days people are using many dufuzzification techniques in their purposed model for automatic washing machines, S. Bahar [6] compared the various defuzzification techniques for the application of an automatic washing machine control design to predict the error difference between different methods, depending upon the amount of inputs and by considering only one output i.e. the wash time. Fuzzy logic empower designers to control tangled systems and remain more fruitful than orthodox approaches. The

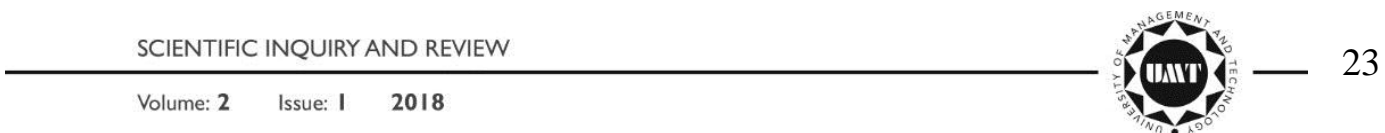


Saqlain, M.and Tariq, F. R.

objective of the current century is also to save time, electricity and water for washing the cloth. S. Hatagar et al. [7] proposed a design for FLC having three inputs to calculate wash time. T. Ahmed et al. [8], compared conventional washing machines with FLC based washing machines and deduced that FLC based machines can choose a right washing time programed in it based on inputs, while in conventional washing machines the user selects the wash time based on his own knowledge or washing experience. M. Akram [9] proposed a design for automatic washing machine having only two inputs and one output. The wash time is obtained by using defuzzification methods.

\subsection{Problem Definition}

$\mathrm{pH}$ of water determines its solubility [10]. When detergents are dissolved in water the solution becomes acidic or basic in nature which is harmful for fabrics [11]. If the water is not neutral due to the variation of $\mathrm{pH}$ of water in different areas, residents end up using more detergent and it takes more time for the cleaning of different types of clothes. It badly affects the economy, fabric, environment and aquatic life. When the $\mathrm{pH}$ of water is not neutral, dissolving detergent in it produces less lather. It means that there is a low amount of detergent for cleaning and rinsing. So, residents of such areas are using more detergent, wasting their time in cleaning of fabrics and are using more electricity for cleaning and rinsing purpose.

\section{2. pH of water}

$\mathrm{pH}$ is a scientific term which indicates the activity of Hydrogen ion (H+). It is also known as the potential of Hydrogen. $\mathrm{pH}$ is a scale of measuring the acidity or alkalinity of a water based solution. A solution is said to be neutral if its $\mathrm{pH}$ is 7 , acidic if $\mathrm{pH}$ is less than 7 and basic if $\mathrm{pH}$ is greater than 7 .

\subsection{Fuzzy Logic Controller}

Fuzzy logic controller mainly consists of three blocks [12].

1. Fuzzifier (the process of converting crisp values into fuzzy)

2. Interface (the rule selector)

3. Defuzzifier (the process of converting fuzzy values into crisp).

\section{Proposed Model of Washing Machine}

Since $\mathrm{pH}$ of water has some impact on washing time so different $\mathrm{pH}$ of water are taken Fuzzy Logic Controller design for automatic washing machine consists of three Linguistic Inputs and one output.

FLC Linguistic Output are

1) Clothtype

2) Dirt type

24

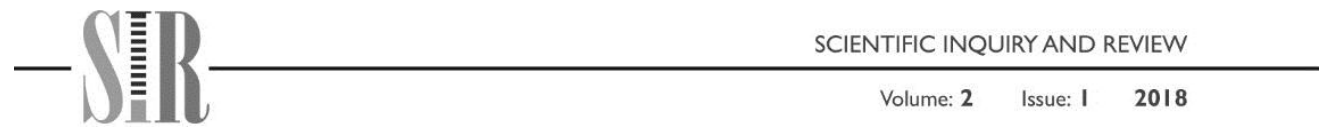


Impact of $\mathrm{pH}$ of Water on Washing Time in Automatic Washing Machine

3) $\mathrm{pH}$ of water

Table 1: The variation of linguistic inputs

\begin{tabular}{|c|c|c|c|}
\hline No. & Cloth type & Dirt type & $\begin{array}{c}\text { pH of } \\
\text { water }\end{array}$ \\
\hline 1 & Jean & Non Oily & 6 \\
\hline 2 & Cotton & Oily & 7 \\
\hline 3 & Parachute & & 8 \\
\hline
\end{tabular}

Table 1 shows the variation of linguistic inputs for the proposed model of washing machine. The above mentioned FLC inference is designed for 18 rules to select Washing Time.

Figure 1 shows basic approach to FLC. Instinctive laundry system based on fuzzy logic controller consists of mainly three blocks i.e. fuzzifier, fuzzy rule selector and defuzzifier. The Membership Function MF of cloth type, dirt type and $\mathrm{pH}$ of water are 1 to 3,1 to 2 and 1 to 3 . MF for wash time is between 1 to 60 .
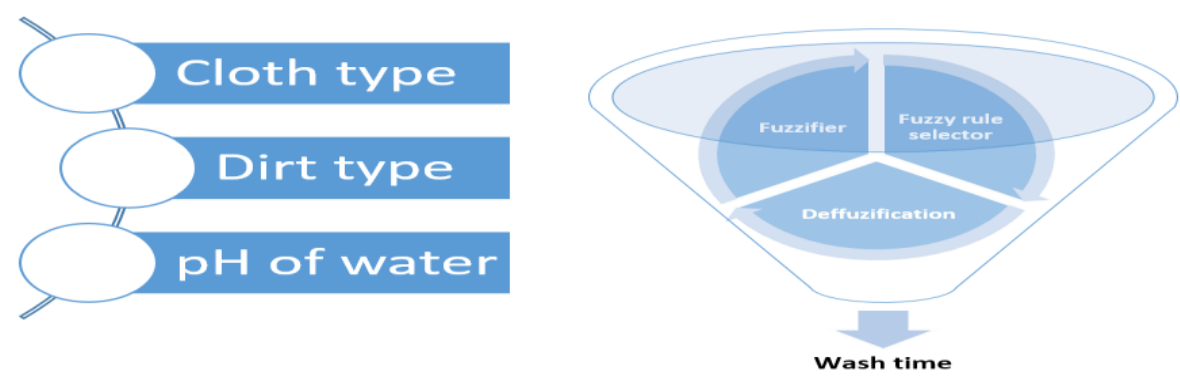

Figure 1: FLC for Washing Machine

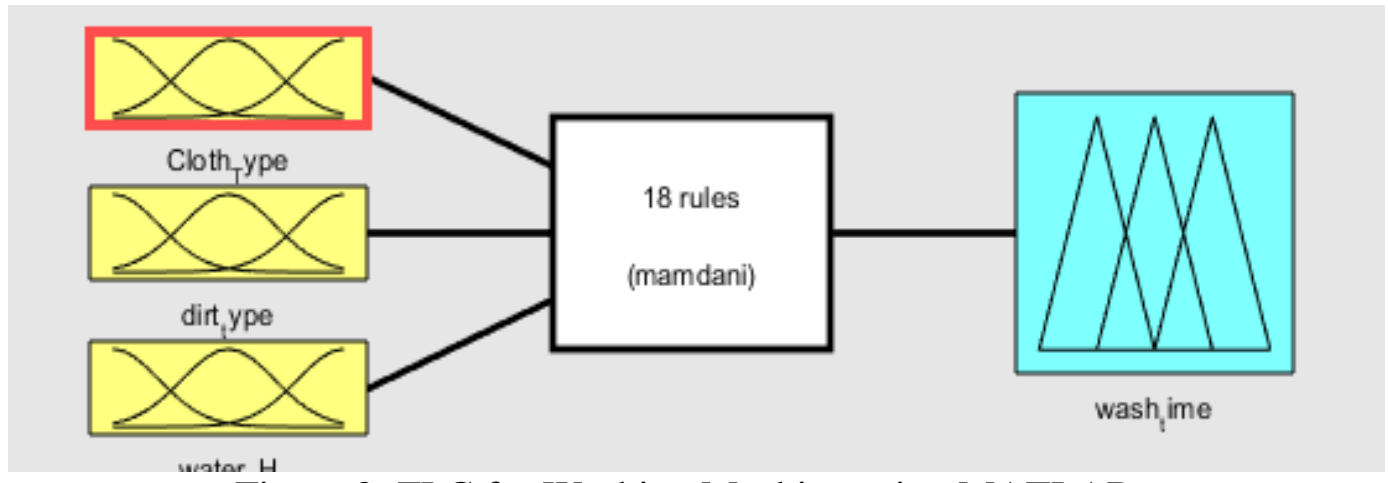

Figure 2: FLC for Washing Machine using MATLAB 
Saqlain, M.and Tariq, F. R.

Table 2: Fuzzy logic Rules

\begin{tabular}{lllll}
\hline & & Linguistic input & & $\begin{array}{l}\text { Linguistic } \\
\text { output } \\
\text { Sr. }\end{array}$ \\
No & Cloth type & Dirt Type & Water pH & Washing time \\
\hline 1 & Jeans & Non Oily & 6 & 30.5 \\
2 & Jeans & Non Oily & 7 & 20.7 \\
3 & Jeans & Non Oily & 8 & 40.3 \\
4 & Cotton & Non Oily & 6 & 20.7 \\
5 & Cotton & Non Oily & 7 & 10.8 \\
6 & Cotton & Non Oily & 8 & 30.5 \\
7 & parachute & Non Oily & 6 & 10.8 \\
8 & parachute & Non Oily & 7 & 4.09 \\
9 & parachute & Non Oily & 8 & 20.7 \\
10 & Jeans & Oily & 6 & 50.2 \\
11 & Jeans & Oily & 7 & 40.3 \\
12 & Jeans & Oily & 8 & 56.9 \\
13 & Cotton & Oily & 6 & 40.3 \\
14 & Cotton & Oily & 7 & 30.5 \\
15 & Cotton & Oily & 8 & 50.2 \\
16 & parachute & Oily & 6 & 40.3 \\
17 & parachute & Oily & 7 & 20.7 \\
18 & parachute & Oily & 8 & 40.1 \\
\hline
\end{tabular}

Table 2 shows all the possible combinations of the above mentioned linguistic inputs of proposed model of automatic washing machine.

The MF of cloth type, dirt type and $\mathrm{pH}$ of water are shown in figure 2(a), 2(b) and 2(c) respectively. 18 rules are formed by using LIs [2] for linguistic output i.e., wash time, is discussed in terms of IF and THEN statements below,

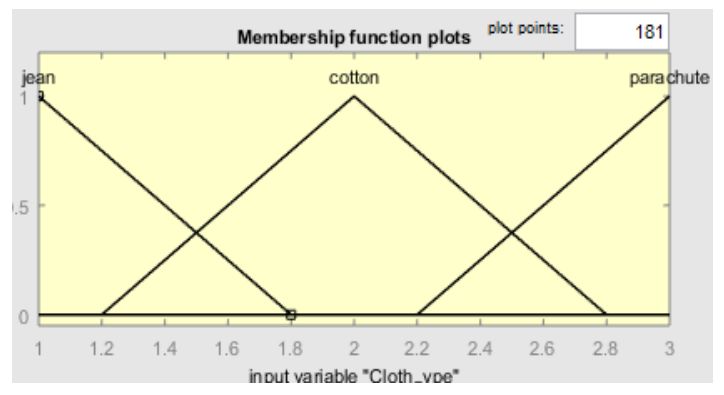

Figure 2(a): MF of cloth type

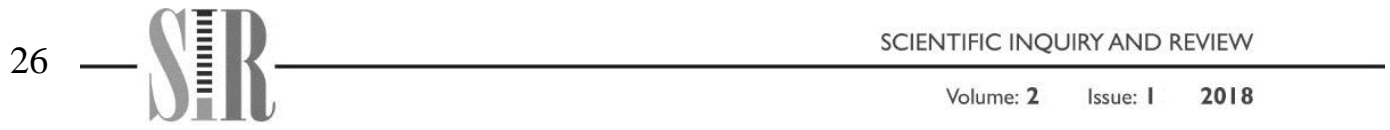




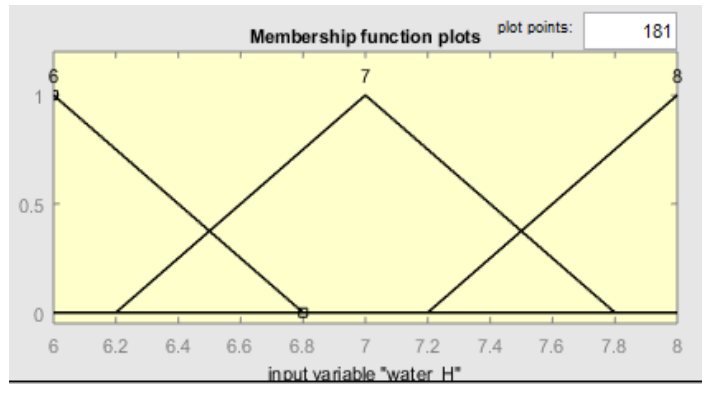

Figure 2(b): MF of dirt type

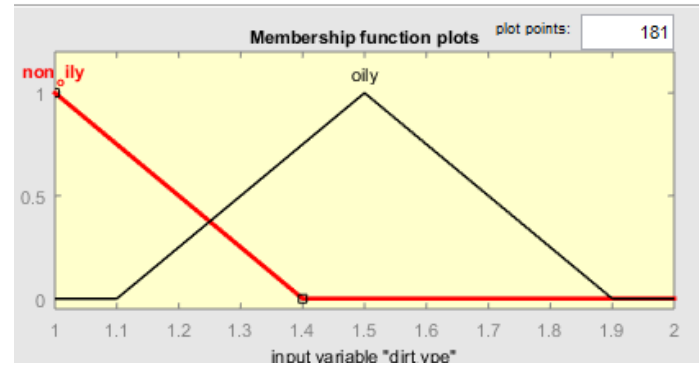

Figure 2(c): $\mathrm{pH}$ of water

The MF of cloth type, dirt type and $\mathrm{pH}$ of water shown in figure 2(a), 2(b) and 2(c) are obtained from MATLAB fuzzy logic toolbox.

Rule 1: IF (cloth type is jean) and (dirt type is non oily) and ( $\mathrm{pH}$ of water is 6) THEN (wash time is $\mathrm{xxxx}$ ).

Rule 2: IF (cloth type is jean) and (dirt type is non oily) and (pH of water is 7) THEN (wash time is $\mathrm{xxx}$ ).

Rule 3: IF (cloth type is jean) and (dirt type is non oily) and (pH of water is 8) THEN (wash time is $\mathrm{xxxxx}$ ).

Rule 4: IF (cloth type is cotton) and (dirt type is non oily) and ( $\mathrm{pH}$ of water is 6) THEN (wash time is $\mathrm{xxx}$ ).

Rule 5: IF (cloth type is cotton) and (dirt type is non oily) and ( $\mathrm{pH}$ of water is 7) THEN (wash time is $\mathrm{xx}$ ).

Rule 6: IF (cloth type is cotton) and (dirt type is non oily) and (pH of water is 8) THEN (wash time is $\mathrm{xxxx}$ ).

Rule 7: IF (cloth type is parachute) and (dirt type is non oily) and (pH of water is 6) THEN (wash time is $\mathrm{xx}$ ).

Rule 8: IF (cloth type is parachute) and (dirt type is non oily) and (pH of water is 7) THEN (wash time is $x$ ).

Rule 9: IF (cloth type is parachute) and (dirt type is non oily) and (pH of water is

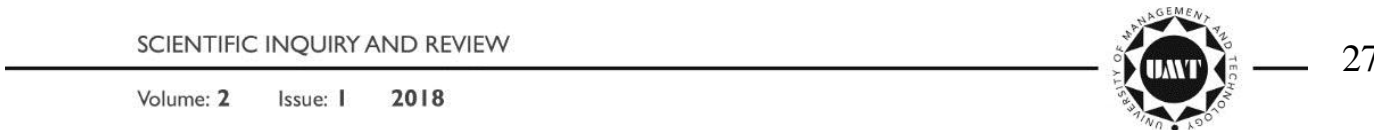


8) THEN (wash time is $\mathrm{xxx}$ ).

Rule 10: IF (cloth type is jean) and (dirt type is oily) and (pH of water is 6) THEN (wash time is $\mathrm{xxxxx}$ ).

Rule 11: IF (cloth type is jean) and (dirt type is oily) and (pH of water is 7) THEN (wash time is xxxx).

Rule 12: IF (cloth type is jean) and (dirt type is oily) and (pH of water is 8) THEN (wash time is $\mathrm{xxxxxx)}$.

Rule 13: IF (cloth type is cotton) and (dirt type is oily) and (pH of water is 6) THEN (wash time is $\mathrm{xxxx}$ ).

Rule 14: IF (cloth type is cotton) and (dirt type is oily) and ( $\mathrm{pH}$ of water is 7) THEN (wash time is $\mathrm{xxx}$ ).

Rule 15: IF (cloth type is cotton) and (dirt type is oily) and (pH of water is 8) THEN (wash time is $\mathrm{xxxxx}$ ).

Rule 16: IF (cloth type is parachute) and (dirt type is oily) and (pH of water is 6) THEN (wash time is $\mathrm{xxx}$ ).

Rule 17: IF (cloth type is parachute) and (dirt type is oily) and ( $\mathrm{pH}$ of water is 7) THEN (wash time is $\mathrm{xx}$ ).

Rule 18: IF (cloth type is parachute) and (dirt type is oily) and ( $\mathrm{pH}$ of water is 8) THEN (wash time is $\mathrm{xxxx}$ ).

\section{Defuzzification:}

The process of Defuzzification is done by using centroid method for the above mentioned rules and the quantified results are obtained from fuzzy interface technique [12].

$$
\text { Wash time }=\bar{X}(\text { Centroid })=\frac{\sum_{1}^{60} x \mu(x)}{\sum_{1}^{60} \mu(x)}
$$

For example rule 7:

$$
\text { Wash time }=\bar{X}(\text { Centroid })=10.8 \mathrm{~min}
$$

\section{Results and Discussions}

\subsection{Effect of Water pH on washing time:}

MATLAB results are shown here for cloth type cotton, dirt type oily and varying $\mathrm{pH}$ of water. Cloth type 2 is assigned to "cotton", dirt type 2 is assigned to "oily" and water $\mathrm{pH}$ are 6,7 and 8 .

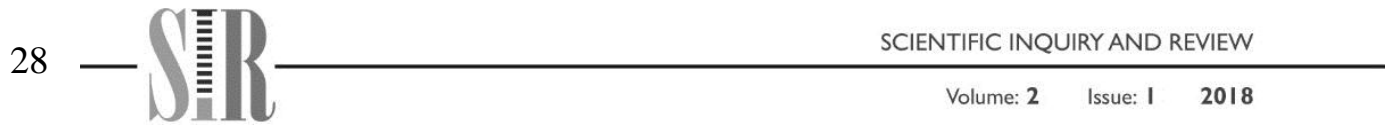




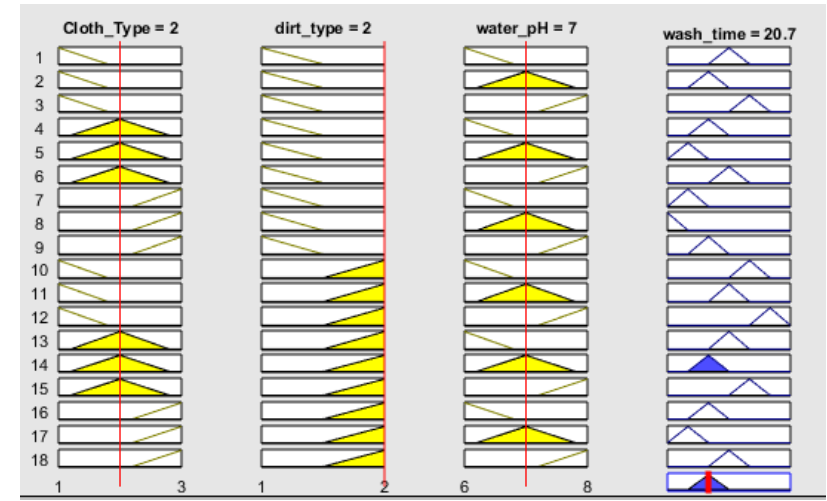

Figure 3(a): Choosing pH 6, cloth type cotton and dirt type oily

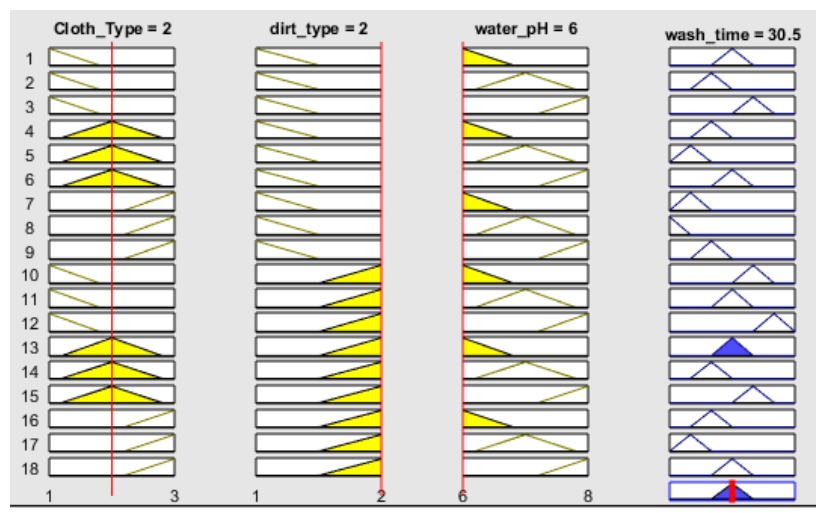

Figure 3(b): Choosing $\mathrm{pH} 7$, cloth type cotton and dirt type oily

Figure 3(a) shows that when we choose water of $\mathrm{pH}$ 6, cloth type cotton and dirt type oily for above mentioned inputs the washing time is 30.5 minutes. Figure 3(b) shows that when we choose water of $\mathrm{pH} 7$, cloth type cotton and dirt type oily for above mentioned inputs the washing time is $20.7 \mathrm{~min}$.

\subsection{Comparison of water $\mathrm{pH}$ and washing time:}

Defuzzified results of MATLAB's fuzzy logic toolbox are shown in table 3 for cloth type cotton, dirt type oily and varying $\mathrm{pH}$ of water.

Table 3: Defuzzified results of MATLAB's fuzzy logic toolbox

\begin{tabular}{cccc}
\hline $\begin{array}{c}\text { Water } \\
\text { pH }\end{array}$ & $\begin{array}{l}\text { Cloth } \\
\text { type }\end{array}$ & $\begin{array}{c}\text { Dirt } \\
\text { type }\end{array}$ & $\begin{array}{c}\text { Washing } \\
\text { Time }\end{array}$ \\
\hline 6 & cotton & oily & 30.5 \\
7 & cotton & oily & 20.7 \\
8 & cotton & oily & 40.3 \\
\hline
\end{tabular}




\subsection{Graphical Comparison of water $\mathrm{pH}$ and washing time:}

Graphically, it can be seen from figure 4 that $\mathrm{pH}$ of water affects washing time. If we increase the $\mathrm{pH}$ of water, washing time also increases. When we choose neutral water, washing time is less than the other $\mathrm{pH}$ alternatives.

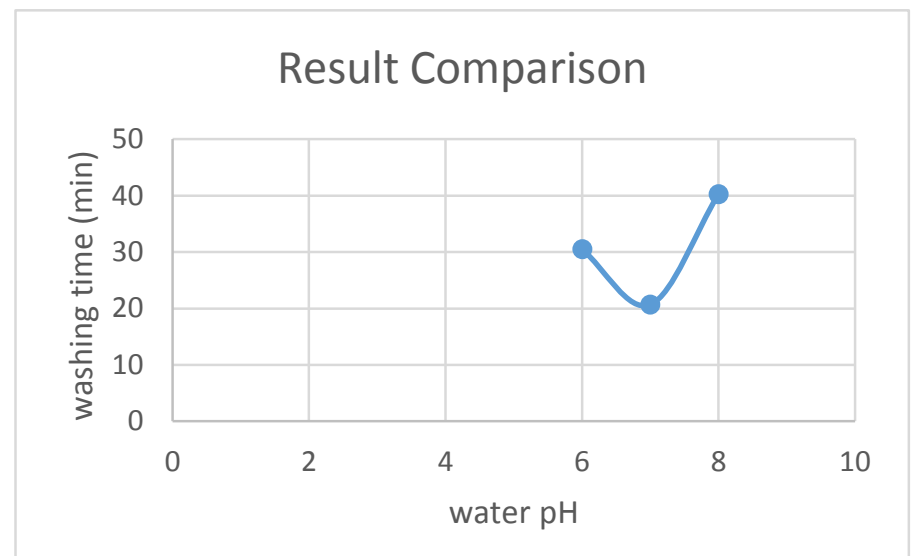

Figure 4: Graphical representations of defuzzified results of MATLAB's fuzzy logic toolbox

\subsection{D surface view of MATLAB results:}

Surface view of aforesaid inputs vs output i.e. cloth type, dirt type, $\mathrm{pH}$ of water and washing time is shown below in figure 5 and figure 6 .

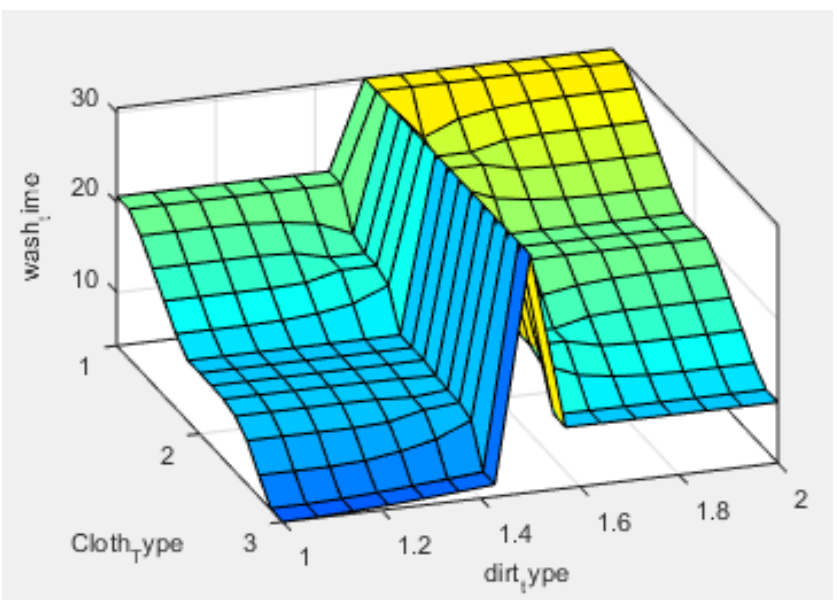

Figure 5: Surface view of inputs vs output 


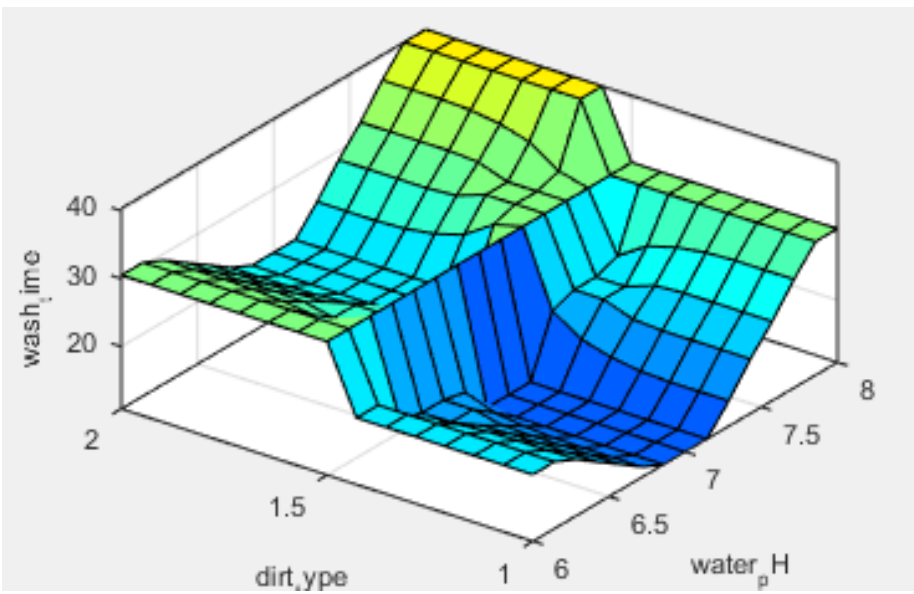

Figure 6: Surface view of inputs vs output

\section{Conclusion}

The result of FLC of the above mentioned inputs clearly shows that by varying $\mathrm{pH}$ of water and type of cloths the output of proposed model, i.e., washing time changes. It also shows that by choosing pure water having $\mathrm{pH} 7$, washing time can be saved up to $40 \%$. So the proposition of the paper is that neutral water $(\mathrm{pH} 7)$ should be used in washing machines. It will not only reduce washing time but will have positive effects also on the environment. In this way, energy and washing time can be saved, which are the basic objectives of current century.

\section{References}

[01] Zadeh LA. Fuzzy Sets. Inform Control. 1965;8(3):338-353.

[02] Mamdani EH. Application of Fuzzy Algorithms for Control of Simple Dynamic Plant. Proc Inst Electr Eng. 1974;121(12):1585-1588.

[03] Han H, Chun-Yi S, Stepanenko Y. Adaptive Control of a Class of Nonlinear Systems with Non-Linearly Parameterized Fuzzy Approximation. IEEE Trans Fuzzy Syst. 2001;9(2):315-323.

[04] Russell WJ. Automatic Control for Washing Machines. Electr Eng. 1942;61(2):89-92.

[05] Agarwal A, Mishra A, Dixit M. Design of an Improved Fuzzy Logic based Control System for Washing Machines. Int J Comput Appl. 2016;151(8):5-10. 
Saqlain, M.and Tariq, F. R.

[06] Soparkar B. Defuzzification in a Fuzzy Logic Controller: Automatic Washing Machine. IJCA Proc Int Conf Comput Technol. 2015;(5):16-19.

[07] Hatagar S, Halase SV. Three Input - One Output Fuzzy logic control of Washing Machine. Int J Sci Res Eng Technol. 2015; 4(1):57-62.

[08] Ahmed T, et al. A Review on Washing Machine Using Fuzzy Logic Controller. Int J Emerging Trends Eng Res. 2016;4(7):64-67.

[09] Akram M, Habib S, Javed I. Intuitionistic fuzzy logic control for washing machines. Indian J Sci Technol. 2014;7(5):654-661.

[10] General Chemistry: Principles, Patterns, and Applications. 5th ed. Washington, DC: Saylor Academy; 2012. Available from:

https://saylordotorg.github.io/text general-chemistry-principlespatterns-and-applications-v1.0/

[11] Household soaps and detergents. J Chem Educ. 1978;55(9):596

[12] Ross TJ. Fuzzy Logic with Engineering Applications. Chennai, India: John Wiley and Sons; 2010. 90-91 p. 